\title{
Downregulation of microRNA-126 is inversely correlated with insulin receptor substrate-1 protein expression in colorectal cancer and is associated with advanced stages of disease
}

\author{
SHICAI YE* , CAIYUAN YU*, GUIXIA ZHANG, FEIXIONG SHI, \\ YONGZE CHEN, JIANYUN YANG, WEIYUN WU and YU ZHOU \\ Department of Gastroenterology, Affiliated Hospital of Guangdong Medical University, \\ Zhanjiang, Guangdong 524001, P.R. China
}

Received January 9, 2020; Accepted May 28, 2020

DOI: $10.3892 / \mathrm{ol} .2020 .11796$

\begin{abstract}
Colorectal cancer (CRC) is a common human malignant tumor, and the fourth most common cause of cancer-associated mortality in China. However, the pathogenesis of CRC is not yet fully understood. The present study aimed to investigate the expression and clinical significance of microRNA (miR)-126 and insulin receptor substrate-1 (IRS-1), as well as the role of miR-126 in the prognosis of patients with CRC. A total of 86 colorectal tissue specimens, including $40 \mathrm{CRC}$ and adjacent normal tissue, 26 colorectal adenoma tissue and 20 normal colorectal tissue samples, were collected for the present study. Reverse transcription-quantitative PCR analysis was performed to determine miR-126 and IRS-1 mRNA expression levels, while western blotting and immunohistochemistry (IHC) analyses were performed to determine IRS-1 protein expression levels. The correlation between miR-126 and IRS-1 expression, as well as the association between altered miR-126 and IRS-1 expression levels and clinicopathological characteristics, and the overall survival time of patients with CRC were assessed. The results demonstrated that miR-126 expression was significantly downregulated, while IRS-1 protein expression was upregulated in CRC tissues compared with that in adjacent normal tissues, colorectal adenoma tissues and normal colorectal tissues, respectively. IHC analysis exhibited strong positive staining of IRS-1 protein in CRC tissues,
\end{abstract}

Correspondence to: Professor Weiyun Wu or Professor Yu Zhou, Department of Gastroenterology, Affiliated Hospital of Guangdong Medical University, 57 South People's Avenue, Zhanjiang, Guangdong 524001, P.R. China

E-mail: winnie556644@163.com

E-mail: ahdg2005@126.com

*Contributed equally

Key words: colorectal cancer, microRNA-126, insulin receptor substrate-1, prognosis, clinicopathological characteristics while absent or weak staining of IRS-1 protein was detected in adjacent normal tissues, colorectal adenoma tissues and normal colorectal tissues. miR-126 expression was inversely correlated with IRS-1 protein expression in CRC tissues $(\mathrm{r}=-0.420 ; \mathrm{P}<0.05)$. Furthermore, downregulated miR-126 expression was associated with advanced clinicopathological characteristics of the disease and a shorter overall survival time in patients with CRC. Taken together, the results of the present study suggest that miR-126 downregulation may be a candidate molecular marker predictive of poor prognosis of patients with CRC.

\section{Introduction}

Colorectal cancer (CRC) is a common human malignancy worldwide and its incidence has significantly increased in recent years, accounting for $8 \%$ of all new cancer diagnoses in 2016; it has become the third most common cancer in the United States (1), and the fifth most common cause of cancer-associated mortality in China, with 191,000 CRC deaths in 2015 (2). Early detection through screening has improved the 5-year survival of patients with CRC; however, the overall prognosis of advanced CRC remains poor due to lack of effective therapeutic strategies (3). Further investigation of the complex molecular networks in the pathogenesis of CRC is required to facilitate the development of novel therapeutic approaches and improve the clinical management of CRC, particularly for patients with advanced stages of the disease.

Previous studies have demonstrated the essential roles of genetic alterations and aberrant expressions of several oncogenes or tumor suppressor genes in the development of CRC $(4,5)$. Whole-exome and genome-scale transcriptome sequencing of seven liver metastases, along with their matched primary tumors and normal tissues showed that, mutations in KRAS, APC, POLE, PTPRT, PLXND1, CELSR3, BAHD1 and PNPLA6 are associated with CRC metastasis (6). Several tumor suppressor genes are associated to CRC carcinogenic process, with the APC, PTEN, FBXW7 and p53 being the common mutated ones in $\mathrm{CRC}$; while oncogenes, including KRAS, CDK8, BRAF, PIK3CA, EGFR, have been shown to 
have mutations in patients with CRC (7). In addition to the protein-coding genes, microRNAs (miRNAs/miRs), a class of non-protein coding small RNAs, have also been reported to play a critical role in CRC tumorigenesis (8).

Mature miRNAs are a class of small, non-coding RNAs, with a length of $\sim 22$ nucleotides. miRNAs mediate the binding of the RNA-induction silencing complex with the 3'-untranslated region (UTR) of target mRNAs and regulate their degradation or translational inhibition (9). miRNAs are involved in several physiological processes, such as cell proliferation, differentiation, apoptosis, individual growth and development, neoplasia and metabolism (10). Thus, altered expression levels of miRNAs have been demonstrated to influence several oncogenic signaling pathways. For example, miR-210-3p promotes prostate cancer cell epithelial-mesenchymal transition and bone metastasis via the $\mathrm{NF}-\kappa \mathrm{B}$ signaling pathway (11). Furthermore, miR-365a-3p regulates JAK-STAT signaling to suppress the proliferation and metastasis of colorectal cancer cells (12). Thus, miRNAs are considered to play critical roles in the pathogenesis of different types of human cancer, including CRC (13). Deregulated expression levels of several miRNAs, including miR-134, miR-320b, miR-766 and miR-19a, have been reported in CRC. A previous study demonstrated that downregulation of miR-134 in CRC leads to overexpression of metastasis-associated genes in colon cancer-1, an oncogenic protein promoting tumor metastasis via deregulation of the hepatocyte growth factor/Met signaling pathway (13). The tumor suppressor role of miR-320b in CRC by inhibition of c-Myc expression has also been reported (14). Furthermore, oncogenic roles of miR-766 and miR-19b have been demonstrated in the pathogenesis of CRC. Overexpression of miR-766 and $\mathrm{miR}-19 \mathrm{~b}$ levels have been reported to promote tumor epithelial-to-mesenchymal transitions and tumor metastasis in CRC $(15,16)$. A previous study indicated that miR-126 expression is deregulated in several CRC cancer cell lines, including SW480, SW620, HT-29 and HCT-116 (17). Subsequent studies have reported similar findings, that miR-126 is downregulated in several types of cancer, including CRC (18-23). Further functional analysis revealed that exogenous overexpression of miR-126 suppresses AKT (also known as protein kinase $\mathrm{B}$ or PKB) and extracellular signal-regulated kinase-1 and -2 (ERK1/2) activation, and inhibits proliferation, migration and invasion of CRC cancer cells (24). Furthermore, in vitro knockdown experiments demonstrated that decreased miR-126 expression in HCT-116 cells leads to AKT and ERK1/2 activation by upregulating insulin receptor substrate-1 (IRS-1) protein expression (24), suggesting a tumor suppressor role of miR-126. However, evidence of altered miR-126 expression and its interplay with IRS-1 in primary CRC tumors remains limited.

IRS-1, a member of the IRS family, is the principle substrate of the insulin-like growth factor I receptor and the insulin receptor, and plays an essential role in cytokine signaling (25). IRS-1 mediates a range of biological responses, including apoptosis and cell differentiation, by binding to and activating enzymes or adapter molecules $(26,27)$. Previous studies have reported that IRS-1 plays an important role in the tumorigenesis of different types of human cancer, including CRC (24). Overexpression of IRS-1 has been detected in CRC and appears to inversely correlate with CRC differentiation, progression and liver metastasis (28). Increasing evidence suggests that the interplay between miR-126 and IRS-1 may notably contribute to colorectal carcinogenesis $(29,30)$.

The present study aimed to investigate the expression statuses of miR-126 and IRS-1 in primary CRC tumors, and to determine the clinical significance of altered miR-126 expression in patients with CRC. The findings would help to determine whether the downregulation of miR-126 expression may play an important role in the pathogenesis and progression of human CRC.

\section{Materials and methods}

Patient specimens. A total of 126 colorectal specimens were collected from patients who underwent surgical resection or colonoscopy biopsy at the Affiliated Hospital of Guangdong Medical University (Zhanjiang, China) between July 2011 and December 2012. The specimens included samples from primary CRC and adjacent normal tissues from 40 patients with CRC, colorectal adenoma tissues from 26 patients who underwent resection of adenomas, and colonoscopy biopsy samples from 20 healthy volunteers. Among the 40 patients with CRC, 20 were men and 20 were women, with a mean age of 56.2 years (age range, 32-73 years). There were 16 men and 10 women, with a mean age of 46 years (age range, 29-65 years) in the colorectal adenoma group. A total of 20 healthy people, including 11 men and 9 women were selected as the control group, with a mean age of 47.5 years (age range, 28-60 years). Adjacent normal colorectal epithelial tissues were $5 \mathrm{~cm}$ away from the edge of the primary tumor. Diagnoses were confirmed via pathological analysis. The specimens were immediately frozen in liquid nitrogen and subsequently stored at $-80^{\circ} \mathrm{C}$ until further experimentation. All specimens were obtained prior to chemotherapy or radiotherapy, and the clinicopathological data of all patients, including sex, age, tumor size, tumor location, pathological data, distant metastasis, Tumor-Node-Metastasis (TNM) staging (31), were recorded and complete. A 5-year follow-up was carried out for all patients, with an average follow-up time of 30.83 months (15-52 months). Follow-up data were conducted using hospital medical records and telephone interviews. The present study was approved by the Medical Ethics Committee of the Affiliated Hospital of Guangdong Medical University, and written informed consent was provided by all participants prior to the study.

Bioinformatics prediction of miR-126 target. Targetscan (http://www.targetscan.org), and PicTar (http://pictar. mdc-berlin.de) databases were used to predict miR-126 targets. The 3'-UTR of IRS-1 mRNA has a putative miR-126 binding site (24).

Reverse transcription-quantitative $(R T-q) P C R$. Total RNA was extracted from tissue specimens, including primary CRC and adjacent normal tissues, colorectal adenoma tissues and normal samples, using RNAiso Plus (Takara Bio, Inc.), according to the manufacturer's protocol, and the purified RNA was stored at $-80^{\circ} \mathrm{C}$ until further use. Total miRNA and mRNA were reverse transcribed into cDNA using the Mir-X miRNA First-Strand Synthesis kit (cat. no. 638315; Clontech Laboratories, Inc.) and PrimeScript ${ }^{\circledR}$ RT Master 
Mix Perfect Real Time (Takara Bio, Inc.), respectively. The following temperature protocol was used for RT: The tube was incubated for $1 \mathrm{~h}$ (miR-126) or $15 \mathrm{~min}$ (IRS-1 mRNA) at $37^{\circ} \mathrm{C}$, then terminated at $85^{\circ} \mathrm{C}$ for $5 \mathrm{~min}$ (miR-126) or $5 \mathrm{sec}$ (IRS-1 mRNA) to inactivate the enzymes. qPCR was subsequently performed using TB Green Premix Ex Taq II (Tli RNaseH Plus; Takara Bio, Inc.), on a LightCycler ${ }^{\circledR}$ (Roche Diagnostics). The universal reverse primer for miR-126 and U6 PCR amplification, mRQ 3' Primer, was included in the Mir-X miRNA First-Strand Synthesis kit, while the remaining primer sequences for miRNA and mRNA were synthesized by Sangon Biotech Co., Ltd. The primer sequences used for qPCR are listed in Table I. The following thermocycling conditions were used for qPCR: Pre-denaturation $\left(95^{\circ} \mathrm{C}\right.$ for $\left.30 \mathrm{sec}\right)$, and 40 cycles of denaturation $\left(95^{\circ} \mathrm{C}\right.$ for $\left.5 \mathrm{sec}\right)$, annealing $\left(60^{\circ} \mathrm{C}\right.$ for $20 \mathrm{sec})$ and extension $\left(65^{\circ} \mathrm{C}\right.$ for $\left.15 \mathrm{sec}\right)$. Relative miR-126 and IRS-1 mRNA expression levels were calculated using the $2^{-\Delta \Delta C q}$ method (32) and normalized to the internal reference genes U6 (miR-126) and $\beta$-actin (IRS-1), respectively. All experiments were performed in triplicate.

Western blotting. Western blotting was performed according to the standard protocol (33). Briefly, total protein was extracted from tissues and cells, using RIPA lysis buffer containing $1 \%$ phenylmethylsulphonyl fluoride (Beyotime Institute of Biotechnology), and concentration was measured using a BCA protein assay kit (Beyotime Institute of Biotechnology). A total of $20 \mu \mathrm{g}$ protein/sample was separated via $10 \%$ SDS-PAGE and subsequently transferred onto polyvinylidene difluoride membranes. The membranes were blocked with $5 \%$ fat-free milk for $1 \mathrm{~h}$ at room temperature and then incubated with rabbit anti-human IRS-1 (1:1,000; cat. no. 2390S; Cell Signaling Technology, Inc.) and mouse anti-human GAPDH (1:1,000; cat. no. AG019; Beyotime Institute of Biotechnology) primary antibodies overnight at $4{ }^{\circ} \mathrm{C}$, prior to incubation with horseradish peroxidase-labeled goat anti-rabbit IgG (1:1,000; cat. no. A0208; Beyotime Institute of Biotechnology) secondary antibody for $1 \mathrm{~h}$ at room temperature. Protein bands were visualized using the enhanced chemiluminescence kit (cat. no. P0018S; Beyotime Institute of Biotechnology) and analyzed using Quantity One image analysis software (version 4.6.6; Bio-Rad Laboratories, Inc.).

Immunohistochemistry (IHC). IHC staining was performed according to the standard protocol (Santa Cruz Biotechnology, Inc.). All tissues were fixed in $4 \%$ paraformaldehyde for at least $24 \mathrm{~h}$ at $4^{\circ} \mathrm{C}$ and embedded in paraffin. Paraffin-embedded tissues were cut into $4-\mu \mathrm{m}$ thick sections and placed onto positively charged slides pretreated with polylysine (Wuhan Boster Biological Technology, Ltd.). The tissue sections were subsequently deparaffinized in xylene, rehydrated in a descending ethanol series $(90,80$ and $70 \%$ for $5 \mathrm{~min}$, respectively) and distilled water, and subjected to heat-induced antigen retrieval in $10 \mathrm{mM}$ citrate buffer $(\mathrm{pH}=6.0)$ (Beijing Solarbio Science and Technology Co., Ltd.) for $5 \mathrm{~min}$ at room temperature. The slides were blocked with $10 \%$ goat serum (Wuhan Boster Biological Technology, Ltd.) for $10 \mathrm{~min}$ at room temperature, prior to incubation with $3 \%$ $\mathrm{H}_{2} \mathrm{O}_{2}$ for $10 \mathrm{~min}$ at room temperature to inhibit endogenous peroxidase activity. Tissue sections were incubated with rabbit anti-human IRS-1 primary antibody (1:50; cat. no. SC-559; Santa Cruz Biotechnology, Inc.) overnight at $4^{\circ} \mathrm{C}$. The slides were washed three times with PBS (Wuhan Boster Biological Technology, Ltd.), prior to incubation with the MaxVision ${ }^{\mathrm{TM}}$ HRP-polymer goat anti-rabbit secondary antibody in the IHC kit (Fuzhou Maixin Biotech Co., Ltd.) for $30 \mathrm{~min}$ at room temperature. The slides were subsequently stained with 3,3'-diaminobenzidine for $10 \mathrm{~min}$ at room temperature to visualize IRS-1 expression and counterstained with hematoxylin for $2 \mathrm{~min}$ at room temperature, prior to mounting in permanent mounting medium. The stained tissue sections were observed under a confocal microscope (magnification, x400; Leica Microsystems, Ltd.). Tissues incubated with PBS instead of the primary antibody were used as negative controls. All experiments were performed in triplicate.

Statistical analysis. Statistical analysis was performed using SPSS software version 13.0 (SPSS, Inc.). All experiments were performed in triplicate and data are presented as the mean \pm standard deviation. One-way analysis of variance, followed by Bonferroni's post-hoc test, was used for multiple intergroup comparisons between miR-126 and IRS-1 mRNA or protein expression levels. Associations between miR-126 or IRS-1 expression and clinicopathological characteristics of patients with CRC were analyzed using the $\chi^{2}$ test. Kaplan-Meier curves and the log-rank test were generated to assess the survival data, while Pearson's correlation analysis was performed to determine the correlation between miR-126 and IRS-1 protein expression. $\mathrm{P}<0.05$ was considered to indicate a statistically significant difference.

\section{Results}

miR-126 is downregulated in CRC. In order to determine the status of miR-126 expression in CRC, RT-qPCR analysis was performed to assess miR-126 expression in 40 primary CRC tissues and their adjacent normal tissues, in 26 colorectal adenomas and in 20 normal colorectal tissues without concomitant CRC. The results demonstrated that miR-126 expression was significantly downregulated in CRC tissues compared with that in matched adjacent normal tissues, colorectal adenoma tissues and normal colorectal tissues, respectively $(\mathrm{P}<0.05$; Fig. 1A). However, no significant differences in miR-126 expression were observed between adjacent normal tissues, colorectal adenoma tissues and normal colorectal tissues, respectively ( $\mathrm{P}>0.05$; Fig. 1A).

Correlation between IRS-1 and miR-126 expression levels in colorectal tissues. The in silico miRNA target prediction analysis demonstrated that IRS-1 is one of the potential downstream targets for miR-126. In order to determine the status of IRS-1 in CRC, and its correlation with miR-126 expression, RT-qPCR and western blot analyses were performed to assess the mRNA and protein expression levels of IRS-1, respectively. No significant differences in IRS-1 mRNA expression were observed between CRC, adjacent tissues, adenoma and normal colorectal tissues (Fig. 1B). However, western blot analysis demonstrated significantly increased IRS-1 protein expression in CRC tissues compared with that in adjacent normal tissues, colorectal adenoma tissues and normal colorectal tissues 
Table I. Primer sequences used for quantitative PCR.

\begin{tabular}{lll}
\hline Name & Direction & \multicolumn{1}{c}{ Primer $\left(5^{\prime} \rightarrow 3^{\prime}\right)$} \\
\hline $\begin{array}{l}\text { miRNA qPCR } \\
\text { miR-126 }\end{array}$ & \\
U6 snRNA & Forward & TCGTACCGTGAGTAATAATGCG \\
Universal qPCR & Forward & mRQ 3' Primer included in the Mir-X miRNA First-Strand Synthesis kit \\
mRNA qPCR & Reverse & \\
IRS-1 & & AGTCCTAACCGCAACCAGAGT \\
& Forward & CCTCAGCCACACATTCTCAA \\
$\beta$-actin & Reverse & GGCGGCAACACCATGTACCCT \\
& Forward & AGGGGCCGGACTCGTCATACT \\
\hline
\end{tabular}

qPCR, quantitative PCR; miRNA/miR, microRNA; snRNA, small nuclear RNA; IRS-1, insulin receptor substrate-1.

A

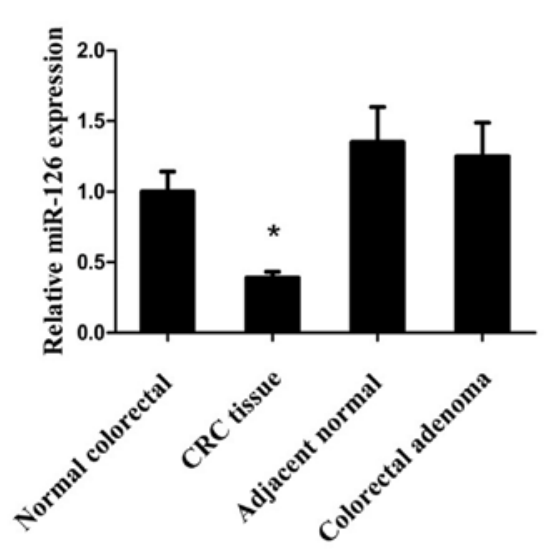

Tissue type
B

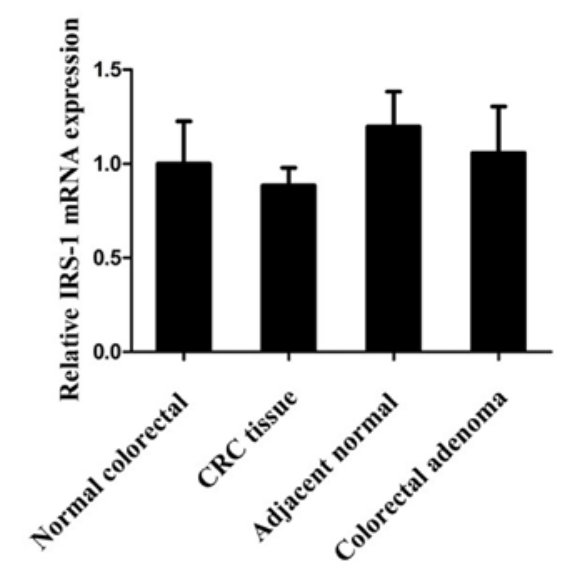

Tissue type

Figure 1. Reverse transcription-quantitative PCR of miR-126 and IRS-1 mRNA expression levels in colorectal tissues. (A) miR-126 expression was significantly downregulated in CRC tissues compared with adjacent normal tissues, colorectal adenoma tissues and normal colorectal tissues, while no significant differences in miR-126 expression levels were observed between adjacent normal tissues, colorectal adenoma tissues and normal colorectal tissues. (B) No significant differences in IRS-1 mRNA expression levels were observed between CRC tissues, adjacent normal tissues, colorectal adenoma tissues and normal colorectal tissues. Data are presented as the mean \pm standard deviation of three independent experiments. ${ }^{*}<0.05$ vs. the other three groups, respectively. miR, microRNA; IRS-1, insulin receptor substrate-1; CRC, colorectal cancer.

$(\mathrm{P}<0.05$; Fig. 2A and B). Furthermore, IHC analysis indicated that IRS-1 protein was strongly expressed in the cytoplasm of CRC tissues (Fig. 2C), but only weakly expressed or absent in the adjacent normal, colorectal adenoma and normal colorectal tissue specimens (Fig. 2D-F).

Pearson's correlation analysis was performed to demonstrate the potential regulatory role of miR-126 in IRS-1 expression. The results demonstrated a significantly inverse correlation between miR-126 and IRS-1 protein expression levels $(\mathrm{r}=-0.420 ; \mathrm{P}<0.05$; Fig. $3 \mathrm{~A})$, while no significant correlation was observed between miR-126 and IRS-1 mRNA expression levels ( $\mathrm{r}=0.028$; $\mathrm{P}>0.05$; Fig. $3 \mathrm{~B})$ in $\mathrm{CRC}$ tissues.

Association between miR-126 and IRS-1 expression levels and clinicopathological characteristics in patients with $C R C$. In order to understand the clinical significance of altered miR-126 expression in patients with CRC, the association between miR-126 and IRS-1 protein expression levels and clinicopathological characteristics of patients with $\mathrm{CRC}$ was assessed. Of the 40 patients with CRC, decreased miR-126 expression and increased IRS-1 expression levels were observed in 29 and 27 cases compared with the levels in the matched adjacent normal tissues, respectively. As presented in Table II, downregulation of miR-126 expression was significantly associated with lymph node $(\mathrm{P}=0.012)$ and distant metastasis $(\mathrm{P}=0.020)$. Similarly, upregulation of IRS-1 protein expression was significantly associated with lymph node metastasis $(\mathrm{P}=0.002)$ and distant metastasis $(\mathrm{P}=0.025)$. Furthermore, low levels of miR-126 expression and high levels of IRS-1 expression were significantly associated with advanced TNM stage (both $\mathrm{P}<0.05$; Table II). However, no significant associations were observed between miR-126 and IRS-1 protein expression 
A

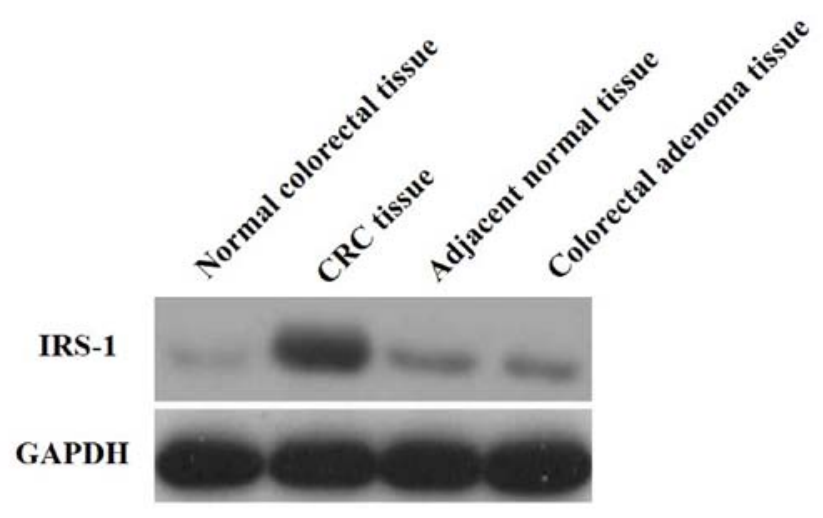

C

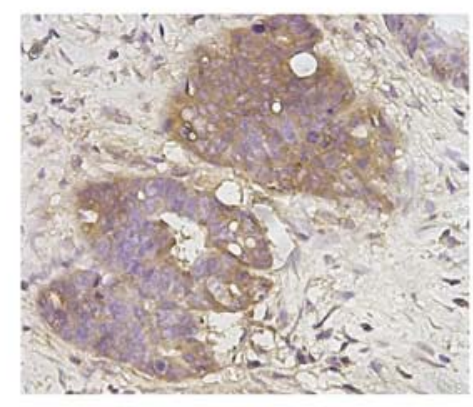

E

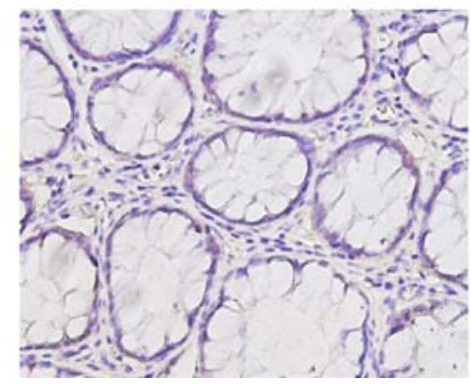

B

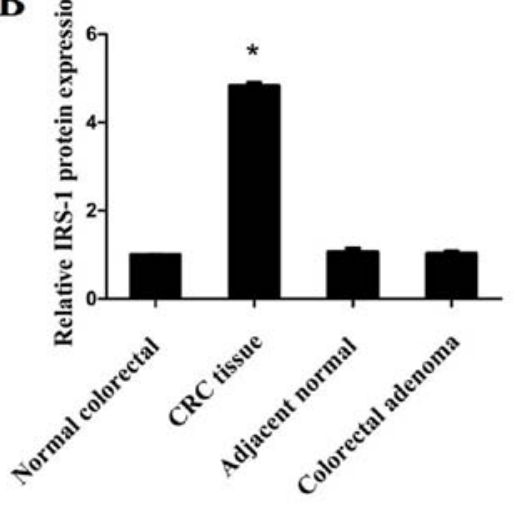

Tissue type

D

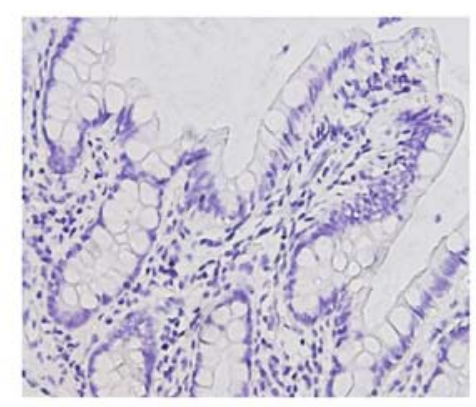

F

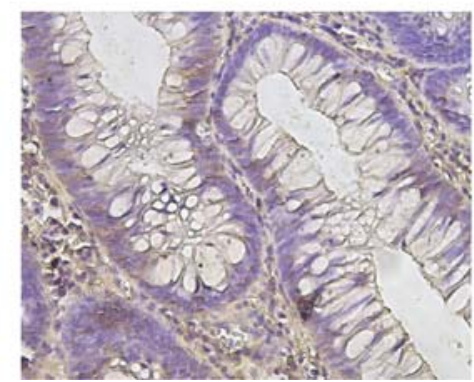

Figure 2. Expression and location of IRS-1 protein in colon tissues. (A) Western blot analysis depicting IRS-1 protein expression in CRC tissues, adjacent normal tissues, colorectal adenoma tissues and normal colorectal tissues. (B) Relative IRS-1 protein expression levels were normalized to GAPDH and presented as the mean \pm standard deviation of three independent experiments. IRS-1 protein expression levels were significantly higher in CRC tissues compared with adjacent normal tissues, colorectal adenoma tissues and normal colorectal tissues. (C-F) Immunohistochemical staining of IRS-1 in colorectal tissues. (C) IRS-1 protein was strongly expressed in the cytoplasm of CRC tissues, and weakly expressed or absent in (D) normal colorectal tissues, (E) adjacent normal tissues and (F) colorectal adenoma tissues. Magnification, $\mathrm{x} 400$. $^{*} \mathrm{P}<0.05$ vs. the other three groups, respectively. IRS-1, insulin receptor substrate-1; $\mathrm{CRC}$, colorectal cancer.

levels and other clinicopathological characteristics in patients with CRC.

Association between miR-126 expression and prognosis of patients with CRC. The association between miR-126 expression and overall survival time was analyzed using the Kaplan-Meier method to determine the prognostic value of miR-126 in patients with CRC. Follow-up survival data was recorded up to 60 months for all 40 patients with $\mathrm{CRC}$. The results demonstrated that patients with $\mathrm{CRC}$, with downregulated miR-126 expression exhibited a significantly shorter overall survival time than those with high miR-126 expression ( $\mathrm{P}=0.0172$; Fig. 4). Taken together, these results suggest that downregulated miR-126 expression may be associated with CRC progression, thus have the potential to act as a candidate molecular marker predictive of a poor prognosis for patients with CRC.

\section{Discussion}

Altered expression of miRNAs has been reported in several types of human cancer, including CRC (34). miRNAs represent a set of biological modulators that can function as either oncogenes or tumor suppressor genes, and play an essential role in complex molecular networks leading to the initiation, progression and metastasis of different types of human cancer (35). For example, miR-92a, miR-140-5p, miR-331-3p, miR-223 and miR-374a were identified as circulating miRNA biomarkers for early diagnosis and monitoring of lung cancer (36). Furthermore, miR-193a-5p and miR-146a-5p 
A

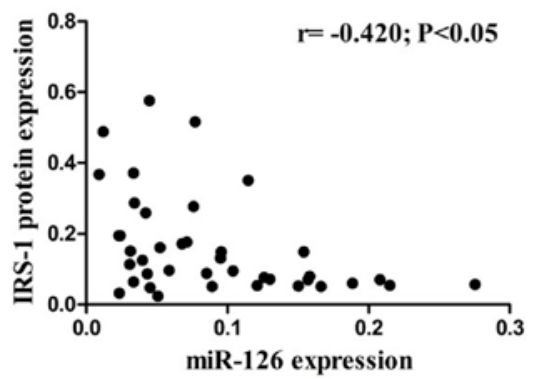

B

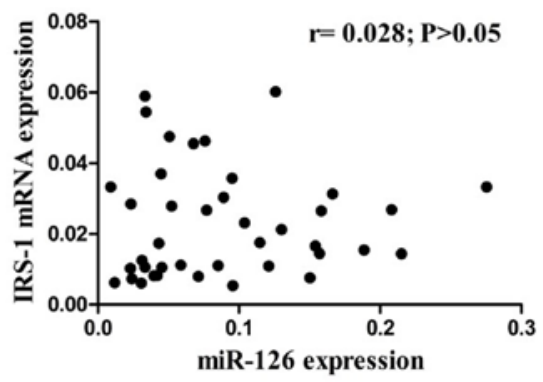

Figure 3. Pearson's correlation analysis between miR-126 and IRS-1 expression levels in human colorectal tissues. (A) miR-126 expression was significantly inversely correlated with IRS-1 protein expression in colorectal cancer tissues. (B) No significant correlation was observed between miR-126 and IRS-1 mRNA expression levels. miR, microRNA; IRS-1, insulin receptor substrate-1.

have been demonstrated to induce $\mathrm{G}_{1}$ arrest in CRC (37). Understanding the roles of miRNA in different types of cancer will provide an important basis for elucidation of molecular mechanisms for human tumorigenesis and the development of novel strategies for clinical management of human cancer.

Diagnostic and prognostic molecular biomarkers have revolutionized clinical strategies for the management of patients with cancer. While the majority of previous studies have primarily focused on genetic and expression markers of protein-coding genes (38-40), only a few studies have investigated the potential roles of miRNA as biomarkers for clinical assessments of different types of human cancer (41-43). A number of studies have performed differential expression analyses of miRNAs in several types of cancer to investigate the role of miRNAs as clinical biomarkers and identified some miRNAs whose aberrant expression levels are associated with pathological and clinical phenotypes of patients with cancer (44-46). Increased miR-210 expression has been reported in several types of cancer, including non-small cell lung cancer (47), glioma (48), CRC (49) and higher expression of miR-210 correlated with worse recurrence free survival or disease free survival (RFS/DFS), overall survival (OS), metastasis free survival or distant relapse free survival (MFS/DRFS) in breast cancer. For RFS/DFS, OS and MFS/DRFS, the combined hazard ratio (HR) and 95\% confidence interval $(95 \% \mathrm{CI})$ of higher miR-210 expression were 3.36 (2.30, 4.93), 3.29 $(1.65,6.58)$ and $2.85(1.76,4.62)$ in patients with breast cancer, respectively (50). Furthermore, increased miR-29c expression, a miRNA molecule regulating T-cell co-regulatory molecule B7-H3, is associated with a shorter overall survival time of patients with breast cancer (51). In non-small cell lung cancer, altered expression levels of miR-429, miR-19b and miR-146a have been reported to be associated with higher TNM stage, lymph node metastasis, unfavorable survival outcomes and poor patient prognosis $(52,53)$. Similarly, altered expression levels of miRNAs have also been demonstrated in CRC. Several miRNAs, including miR-200a (54), miR-16 (55) and miR-30b (56), have been demonstrated to be associated with a number of clinical features in patients with CRC, including poor differentiation of tumor, high TNM stages, lymph node status and distant metastasis. Furthermore, altered expression levels of these miRNAs were also demonstrated to independently predict clinical outcomes (recurrence and survival) of patients with CRC $(55,57,58)$. miR-126 is regarded as an important tumor suppressor, whereby its downregulation has been detected in several types of cancer, including CRC, lung cancer and breast cancer (59-62). However, the associations between miR-126 expression and pathological features and clinical outcomes of patients with CRC have not been extensively investigated.

The present study assessed miR-126 expression in a small cohort of patients with CRC, with recorded pathological characteristics and clinical outcomes. The results demonstrated that miR-126 was downregulated in CRC tumors, which was significantly associated with advanced TNM and Dukes stages of tumor, positive lymph node status and distant metastasis. Furthermore, Kaplan-Meier survival analysis indicated that downregulation of miR-126 expression was significantly associated with a shorter overall survival time of patients with CRC. Taken together, the results of the present study suggest that miR-126 expression may be a potential candidate molecular marker predictive of the progression and prognosis of patients with CRC.

Previous studies have investigated the functional and mechanical roles of miRNAs in different types of human cancer $(18,48,52)$. In CRC, several miRNAs have been identified to be critical molecular regulators interplaying with important molecular pathways, and thus play key roles in the initiation and progression of CRC $(24,54,56)$. A previous study demonstrated that miR-30b targets oncogenic KRAS, PIK3CD and BCL2, and regulates functional activities of the MAPK and PI3K signaling pathways (58). Thus, downregulation of miR-30b expression may serve as an alternative mechanism for the activation of its downstream oncogenic signaling pathways (58). Previous studies have indicated the underlying molecular mechanisms of miR-126 as a tumor suppressor in different types of human cancer. For example, in vitro analysis of thyroid cancer cells demonstrated that overexpression of miR-126 inhibits cell proliferation, migration and invasion by targeting the C-X-C motif chemokine receptor 4 (61). Another in vitro experiment indicated that overexpression of miR-126 suppresses cell cycle progression from $\mathrm{G}_{1} / \mathrm{G}_{0}$ phase to $S$ phase in the breast cancer MSF-7 cell line (60).

The mechanistic roles of miR-126 in CRC tumorigenesis and progression have not yet been fully investigated. A previous 
Table II. Association between miR-126 and IRS-1 protein expression levels and clinicopathological characteristics in patients with CRC ( $=40)$.

\begin{tabular}{|c|c|c|c|c|c|c|}
\hline \multirow[b]{2}{*}{ Characteristic } & \multicolumn{2}{|c|}{ miR-126 expression, $\mathrm{n}$} & \multirow[b]{2}{*}{ P-value } & \multicolumn{2}{|c|}{ IRS-1 expression, $\mathrm{n}$} & \multirow[b]{2}{*}{ P-value } \\
\hline & Upregulated & Downregulated & & Upregulated & Downregulated & \\
\hline Total number of patients & 11 & 29 & & 27 & 13 & \\
\hline \multicolumn{7}{|l|}{ Age, years } \\
\hline 60 & 7 & 16 & 0.900 & 14 & 9 & 0.484 \\
\hline$<60$ & 4 & 13 & & 13 & 4 & \\
\hline \multicolumn{7}{|l|}{ Sex } \\
\hline Male & 5 & 15 & 0.723 & 15 & 5 & 0.311 \\
\hline Female & 6 & 14 & & 12 & 8 & \\
\hline \multicolumn{7}{|l|}{ TNM stage } \\
\hline Tis, $\mathrm{T} 1, \mathrm{~T} 2$ & 8 & 8 & 0.025 & 5 & 11 & $<0.001$ \\
\hline $\mathrm{T} 3, \mathrm{~T} 4$ & 3 & 21 & & 22 & 2 & \\
\hline \multicolumn{7}{|l|}{ Diameter, cm } \\
\hline$\geq 5$ & 4 & 14 & $>0.999$ & 12 & 6 & 0.919 \\
\hline$<5$ & 7 & 15 & & 15 & 7 & \\
\hline \multicolumn{7}{|l|}{ Tumor location } \\
\hline $\mathrm{C}, \mathrm{A}, \mathrm{T}$ & 5 & 16 & 0.583 & 16 & 5 & 0.217 \\
\hline $\mathrm{D}, \mathrm{S}, \mathrm{R}$ & 6 & 13 & & 11 & 8 & \\
\hline \multicolumn{7}{|l|}{ Histological type } \\
\hline Well and moderate & 3 & 12 & 0.648 & 13 & 2 & 0.098 \\
\hline Poor & 8 & 17 & & 14 & 11 & \\
\hline \multicolumn{7}{|l|}{ Lymph node metastasis } \\
\hline Positive & 2 & 20 & 0.012 & 20 & 2 & 0.002 \\
\hline Negative & 9 & 9 & & 7 & 11 & \\
\hline \multicolumn{7}{|l|}{ Distant metastasis } \\
\hline Positive & 2 & 19 & 0.020 & 18 & 3 & 0.025 \\
\hline Negative & 9 & 10 & & 9 & 10 & \\
\hline
\end{tabular}

miR, microRNA; IRS-1, insulin receptor substrate-1; TNM, Tumor-Node-Metastasis; C, cecum; A, ascending colon; T, transverse colon; $\mathrm{D}$, descending colon; S, sigmoid colon; R, rectum.

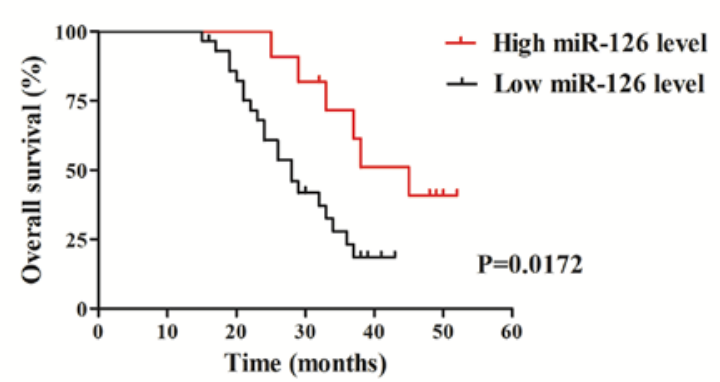

Figure 4. Kaplan-Meier survival analysis of patients with CRC, based on miR-126 expression level. Downregulated miR-126 expression was associated with a significantly shorter overall survival time of patients with CRC. CRC, colorectal cancer; miR, microRNA.

study used in vitro CRC cell line models and demonstrated that miR-126 functionally targets the IRS-1 gene and regulates IRS-1 expression in CRC cells (24). IRS-1 has been demonstrated to possess an oncogenic property, which can lead to activation of the AKT and MAPK signaling pathways (63). Increased IRS-1 expression is functionally associated with enhanced cell proliferation and migration, loss of differentiation and liver metastasis in CRC (28,63-66). However, to the best of our knowledge, there is currently no evidence of the interplay between miR-126 and IRS-1 in primary CRC. Thus, the present study simultaneously analyzed the expression levels of miR-126 and IRS-1 mRNA, as well as IRS-1 protein levels in primary CRC tumors, and successfully provided the first in vivo evidence demonstrating the potential interplay between miR-126 and IRS-1 in CRC tumorigenesis. The results of the present study demonstrated that downregulation of miR-126 expression was significantly associated with increased IRS-1 protein levels in primary CRC tumors, whereas no significant association was observed with IRS-1 mRNA expression levels. These results suggest that miR-126 mechanistically regulates IRS-1 expression by blocking IRS-1 protein translation, rather than targeting IRS-1 mRNA degradation in primary 
CRC tumors. Taken together, the results of the present study suggest that miR-126 is a candidate tumor suppressor for CRC and may serve as a potential biomarker for clinical assessment of patients with CRC. However, due to the small sample size used in the present study, multivariate analysis could not be performed, thus the effects of potential confounding factors was not assessed. Therefore, prospective studies will include larger sample sizes in order to provide sufficient evidence to determine the role of miR-126 in CRC.

In conclusion, the results of the present study demonstrated that miR-126 expression was significantly downregulated in CRC tissues and inversely correlated with IRS -1 protein expression. Furthermore, downregulation of miR-126 expression was associated with advanced stages of the disease and a poor prognosis in patients with CRC. Taken together, these results suggest that miR-126 may function as a tumor suppressor and play an important role in CRC carcinogenesis and progression.

\section{Acknowledgements}

The authors of the present study would like to thank Professor Zhe Wang from the Department of Gastrointestinal Surgery at the Affiliated Hospital of Guangdong Medical University (Zhanjiang, China) for providing the surgical specimens and collecting the clinical information.

\section{Funding}

No funding was received.

\section{Availability of data and materials}

The datasets used and/or analyzed during the current study are available from the corresponding author upon reasonable request.

\section{Authors' contributions}

YZ designed the present study. SY,CY,GZ,FS, YC,JY and WW performed the experiments. SY, CY, WW and YZ performed the statistical analysis and drafted the initial manuscript, while WW and YZ critically revised the manuscript for important intellectual content. All authors read and approved the final manuscript.

\section{Ethics approval and consent to participate}

The present study was approved by the Ethics Committees of the Affiliated Hospital of Guangdong Medical University (Zhanjiang, China; approval no. NPJ2011005), and written informed consent was provided by all participants prior to the study.

\section{Patient consent for publication}

Not applicable.

\section{Competing interests}

The authors declare that they have no competing interests.

\section{References}

1. Siegel RL, Miller KD and Jemal A: Cancer statistics, 2016. CA Cancer J Clin 66: 7-30, 2016.

2. Chen W, Zheng R, Baade PD, Zhang S, Zeng H, Bray F, Jemal A, $\mathrm{Yu}$ XQ and He J: Cancer statistics in China, 2015. CA Cancer J Clin 66: 115-132, 2016.

3. Ganesh K, Stadler ZK, Cercek A, Mendelsohn RB, Shia J, Segal NH and Diaz LA Jr: Immunotherapy in colorectal cancer: Rationale, challenges and potential. Nat Rev Gastroenterol Hepatol 16: 361-375, 2019.

4. Harris TJ and McCormick F: The molecular pathology of cancer. Nat Rev Clin Oncol 7: 251-265, 2010.

5. Mármol I, Sánchez-de-Diego C, Pradilla Dieste A, Cerrada E and Rodriguez Yoldi MJ: Colorectal carcinoma: A general overview and future perspectives in colorectal cancer. Int J Mol Sci 18: 197, 2017.

6. Goryca K, Kulecka M, Paziewska A, Dabrowska M, Grzelak M, Skrzypczak M, Ginalski K, Mroz A, Rutkowski A, Paczkowska K, et al: Exome scale map of genetic alterations promoting metastasis in colorectal cancer. BMC Genet 19: 85, 2018.

7. Fearon ER: Molecular genetics of colorectal cancer. Annu Rev Pathol 6: 479-507, 2011.

8. Valeri N, Gasparini P, Fabbri M, Braconi C, Veronese A, Lovat F, Adair B, Vannini I, Fanini F, Bottoni A, et al: Modulation of mismatch repair and genomic stability by miR-155. Proc Natl Acad Sci USA 107: 6982-6987, 2010.

9. van den Berg A, Mols J and Han J: RISC-target interaction: Cleavage and translational suppression. Biochim Biophys Acta 1779: 668-677, 2008.

10. Bartel DP: MicroRNAs: Genomics, biogenesis, mechanism, and function. Cell 116: 281-297, 2004.

11. Ren D, Yang Q, Dai Y, Guo W, Du H, Song L and Peng X: Oncogenic miR-210-3p promotes prostate cancer cell EMT and bone metastasis via NF- $\mathrm{kB}$ signaling pathway. Mol Cancer 16: $117,2017$.

12. Hong YG, Xin C, Zheng H, Huang ZP, Yang Y, Zhou JD, Gao XH, Hao L, Liu QZ, Zhang W and Hao LQ: miR-365a-3p regulates ADAM10-JAK-STAT signaling to suppress the growth and metastasis of colorectal cancer cells. J Cancer 11: 3634-3644, 2020.

13. Zhang Y, Wang Z, Chen M, Peng L, Wang X, Ma Q, Ma F and Jiang B: MicroRNA-143 targets MACC1 to inhibit cell invasion and migration in colorectal cancer. Mol Cancer 11: 23, 2012.

14. Wang H, Cao F, Li X, Miao H, E J, Xing J and Fu CG: miR-320b suppresses cell proliferation by targeting c-Myc in human colorectal cancer cells. BMC Cancer 15: 748, 2015.

15. Li YC, Li CF, Chen LB, Li DD, Yang L, Jin JP and Zhang B: MicroRNA-766 targeting regulation of SOX6 expression promoted cell proliferation of human colorectal cancer. Onco Targets Ther 8: 2981-2988, 2015.

16. Huang L, Wang X, Wen C, Yang X, Song M, Chen J, Wang C, Zhang B, Wang L, Iwamoto A, et al: Hsa-miR-19a is associated with lymph metastasis and mediates the TNF- $\alpha$ induced epithelial-to-mesenchymal transition in colorectal cancer. Sci Rep 5: 13350, 2015.

17. Liu Y,Zhou Y, Feng X, An P, Quan X, Wang H, Ye S, Yu C, He Y and Luo H: MicroRNA-126 functions as a tumor suppressor in colorectal cancer cells by targeting CXCR4 via the AKT and ERK1/2 signaling pathways. Int J Oncol 44: 203-210, 2014.

18. Feng R, Chen X, Yu Y, Su L, Yu B, Li J, Cai Q, Yan M, Liu B and Zhu Z: miR-126 functions as a tumour suppressor in human gastric cancer. Cancer Lett 298: 50-63, 2010.

19. Li X, Shen Y, Ichikawa H, Antes T and Goldberg GS: Regulation of miRNA expression by Src and contact normalization: Effects on nonanchored cell growth and migration. Oncogene 28: 4272-4283, 2009.

20. Crawford M, Brawner E, Batte K, Yu L, Hunter MG, Otterson GA, Nuovo G, Marsh CB and Nana-Sinkam SP: MicroRNA-126 inhibits invasion in non-small cell lung carcinoma cell lines. Biochem Biophys Res Commun 373: 607-612, 2008.

21. Saito Y, Friedman JM, Chihara Y, Egger G, Chuang JC and Liang G: Epigenetic therapy upregulates the tumor suppressor microRNA-126 and its host gene EGFL7 in human cancer cells. Biochem Biophys Res Commun 379: 726-731, 2009.

22. Li XM, Wang AM, Zhang J and Yi H: Down-regulation of miR-126 expression in colorectal cancer and its clinical significance. Med Oncol 28: 1054-1057, 2011.

23. Li Z, Li N, Wu M, Li X, Luo Z and Wang X: Expression of miR-126 suppresses migration and invasion of colon cancer cells by targeting CXCR4. Mol Cell Biochem 381: 233-242, 2013. 
24. Zhou Y, Feng X, Liu YL, Ye SC, Wang H, Tan WK, Tian T, Qiu YM and Luo HS: Down-regulation of miR-126 is associated with colorectal cancer cells proliferation, migration and invasion by targeting IRS-1 via the AKT and ERK1/2 signaling pathways PLoS One 8: e81203, 2013.

25. Dumpati R, Ramatenki V, Vadija R, Vellanki S and Vuruputuri U: Structural insights into suppressor of cytokine signaling 1 protein-identification of new leads for type 2 diabetes mellitus. J Mol Recognit 31: e2706, 2018.

26. White MF: The IRS-signalling system: A network of docking proteins that mediate insulin action. Mol Cell Biochem 182: 3-11, 1998.

27. Chang Q, Li Y, White MF, Fletcher JA and Xiao S: Constitutive activation of insulin receptor substrate 1 is a frequent event in human tumors: Therapeutic implications. Cancer Res 62: 6035-6038, 2002.

28. Esposito DL, Aru F, Lattanzio R, Morgano A, Abbondanza M, Malekzadeh R, Bishehsari F, Valanzano R, Russo A, Piantelli M, et al: The insulin receptor substrate 1 (IRS1) in intestinal epithelial differentiation and in colorectal cancer. PLoS One 7: e36190, 2012.

29. Esposito DL, Verginelli F, Toracchio S, Mammarella S De Lellis L, Vanni C, Russo A, Mariani-Costantini R and Cama A: Novel insulin receptor substrate 1 and 2 variants in breast and colorectal cancer. Oncol Rep 30: 1553-1560, 2013

30. Li N, Li X, Huang S, Shen S and Wang X: miR-126 inhibits colon cancer proliferation and invasion through targeting IRS1, SLC7A5 and TOM1 gene. Zhong Nan Da Xue Xue Bao Yi Xue Ban 38: 809-817, 2013 (In Chinese).

31. Sorbin LH, Gospodarowicz MK and Wittekind C (eds): International Union against Cancer (UICC). TNM classification of malignant tumors. 7 edition. West Sussex, UK, Wiley-Blackwell, 2009.

32. Livak KJ and Schmittgen TD: Analysis of relative gene expression data using real-time quantitative PCR and the 2(-Delta Delta C(T)) method. Methods 25: 402-408, 2001.

33. Kurien BT and Scofield RH: Western blotting: An introduction. Methods Mol Biol 1312: 17-30, 2015.

34. Calin GA and Croce CM: MicroRNA signatures in human cancers. Nat Rev Cancer 6: 857-866, 2006.

35. Chen WS, Chen TW, Yang TH, Hu LY, Pan HW, Leung CM, Li SC, Ho MR, Shu CW, Liu PF, et al: Co-modulated behavio and effects of differentially expressed miRNA in colorectal cancer. BMC Genomics 14 (Suppl 5): S12, 2013.

36. Zhang YH, Jin M, Li J and Kong X: Identifying circulating miRNA biomarkers for early diagnosis and monitoring of lung cancer. Biochim Biophys Acta Mol Basis Dis: 165847, 2020 (Epub ahead of print).

37. Noorolyai S, Baghbani E, Aghebati Maleki L, Baghbanzadeh Kojabad A, Shanehbansdi D, Khaze Shahgoli V, Mokhtarzadeh A and Baradaran B: Restoration of miR-193a-5p and miR-146 a-5p expression induces G1 arrest in colorectal cancer through targeting of MDM2/p53. Adv Pharm Bull 10: 130-134, 2020.

38. Li XQ, Li L, Xiao CH and Feng YM: NEFL mRNA expression level is a prognostic factor for early-stage breast cancer patients. PLoS One 7: e31146, 2012

39. Salvatore L, Calegari MA, Loupakis F, Fassan M, Di Stefano B, Bensi M, Bria E and Tortora G: PTEN in colorectal cancer: Shedding light on its role as predictor and target. Cancers (Basel) 11: 1765, 2019.

40. Li Z, Xue TQ, Yang C, Wang YL, Zhu XL and Ni CF: EGFL7 promotes hepatocellular carcinoma cell proliferation and inhibits cell apoptosis through increasing CKS2 expression by activating Wnt/ $\beta$-catenin signaling. J Cell Biochem 119: 10327-10337, 2018.

41. Lee YS and Dutta A: MicroRNAs in cancer. Annu Rev Pathol 4 199-227, 2009.

42. Tachibana H, Sho R, Takeda Y, Zhang X, Yoshida Y, Narimatsu H, Otani K, Ishikawa S, Fukao A, Asao H and Iino M: Circulating miR-223 in oral cancer: Its potential as a novel diagnostic biomarker and therapeutic target. PLoS One 11: e0159693, 2016.

43. Wang J,Zhou Y, Fei X, Chen X and Zhu Z: Regulator of G-protein signaling 3 targeted by miR-126 correlates with poor prognosis in gastric cancer patients. Anticancer Drugs 28: 161-169, 2017.

44. Zhang H, Mao F, Shen T, Luo Q, Ding Z, Qian L and Huang J: Plasma miR-145, miR-20a, miR-21 and miR-223 as novel biomarkers for screening early-stage non-small cell lung cancer. Oncol Lett 13: 669-676, 2017.

45. Ruan L and Qian X: MiR-16-5p inhibits breast cancer by reducing AKT3 to restrain NF- $\kappa$ B pathway. Biosci Rep 39: BSR20191611, 2019

46. Shi XY, Wang H, Wang W and Gu YH: MiR-98-5p regulates proliferation and metastasis of MCF-7 breast cancer cells by targeting Gab2. Eur Rev Med Pharmacol Sci 23: 2847-2855, 2019.
47. Yang F, Yan Y, Yang Z, Hong X, Wang M, Yang Y, Ye L and Liu B: miR-210 in exosomes derived from CAFs promotes non-small cell lung cancer migration and invasion through PTEN/PI3K/AKT pathway. Cell Signal 73: 109675, 2020 (Epub ahead of print).

48. Lan F, Yue X and Xia T: Exosomal microRNA-210 is a potentially non-invasive biomarker for the diagnosis and prognosis of glioma. Oncol Lett 19: 1967-1974, 2020.

49. Wang W, Qu A, Liu W, Liu Y, Zheng G, Du L, Zhang X, Yang Y, Wang $\mathrm{C}$ and Chen $\mathrm{X}$ : Circulating miR-210 as a diagnostic and prognostic biomarker for colorectal cancer. Eur J Cancer Care: 22 Feb, 2016(Epub ahead of print)

50. Li M, Ma X,Li M,Zhang B, Huang J, Liu L and Wei Y: Prognostic role of microRNA-210 in various carcinomas: A systematic review and meta-analysis. Dis Markers 2014: 106197, 2014.

51. Nygren MK, Tekle C, Ingebrigtsen VA, Mäkelä R, Krohn M, Aure MR, Nunes-Xavier CE, Perälä M, Tramm T, Alsner J, et al: Identifying microRNAs regulating B7-H3 in breast cancer: The clinical impact of microRNA-29c. Br J Cancer 110: 2072-2080, 2014.

52. Zhu W, He J, Chen D, Zhang B, Xu L, Ma H, Liu X, Zhang Y and $\mathrm{Le} \mathrm{H}$ : Expression of miR-29c, miR-93, and miR-429 as potential biomarkers for detection of early stage non-small lung cancer. PLoS One 9: e87780, 2014

53. Wu C, Cao Y, He Z, He J, Hu C, Duan H and Jiang J: Serum levels of miR-19b and miR-146a as prognostic biomarkers for non-small cell lung cancer. Tohoku J Exp Med 232: 85-95, 2014.

54. Li Y, Sun J, Cai Y, Jiang Y, Wang X, Huang X, Yin Y and Li H: MiR-200a acts as an oncogene in colorectal carcinoma by targeting PTEN. Exp Mol Pathol 101: 308-313, 2016.

55. Qian J, Jiang B, Li M, Chen J and Fang M: Prognostic significance of microRNA-16 expression in human colorectal cancer. World J Surg 37: 2944-2949, 2013.

56. Zhao H, Xu Z, Qin H, Gao Z and Gao L: miR-30b regulates migration and invasion of human colorectal cancer via SIX1. Biochem J 460: 117-125, 2014.

57. Pichler M, Ress AL, Winter E, Stiegelbauer V, Karbiener M, Schwarzenbacher D, Scheideler M, Ivan C, Jahn SW, Kiesslich T, et al: MiR-200a regulates epithelial to mesenchymal transition-related gene expression and determines prognosis in colorectal cancer patients. Br J Cancer 110: 1614-1621, 2014.

58. Liao WT, Ye YP, Zhang NJ, Li TT, Wang SY, Cui YM, Qi L, Wu P, Jiao HL, Xie YJ, et al: MicroRNA-30b functions as a tumour suppressor in human colorectal cancer by targeting KRAS, PIK3CD and BCL2. J Pathol 232: 415-427, 2014.

59. Liu Y, Zhou Y, Feng X, Yang P, Yang J, An P, Wang H, Ye S, $\mathrm{Yu}$ C, He Y and Luo H: Low expression of microRNA-126 is associated with poor prognosis in colorectal cancer. Genes Chromosomes Cancer 53: 358-365, 2014.

60. Dong Y, Fu C, Guan H, Zhang Z, Zhou T and Li B: Prognostic significance of miR-126 in various cancers: A meta-analysis. Onco Targets Ther 9: 2547-2555, 2016.

61. Qian Y, Wang X, Lv Z, Guo C, Yang Y, Zhang J and Wang X: MicroRNA-126 is downregulated in thyroid cancer cells, and regulates proliferation, migration and invasion by targeting CXCR4. Mol Med Rep 14: 453-459, 2016.

62. Ebrahimi F, Gopalan V, Wahab R, Lu CT, Smith RA and Lam AK: Deregulation of miR-126 expression in colorectal cancer pathogenesis and its clinical significance. Exp Cell Res 339: 333-341, 2015

63. Wu L, Shi B, Huang K and Fan G: MicroRNA-128 suppresses cell growth and metastasis in colorectal carcinoma by targeting IRS1. Oncol Rep 34: 2797-2805, 2015

64. Yin Y, Yan ZP, Lu NN, Xu Q, He J, Qian X, Yu J, Guan X, Jiang BH and Liu LZ: Downregulation of miR-145 associated with cancer progression and VEGF transcriptional activation by targeting N-RAS and IRS1. Biochim Biophys Acta 1829: 239-247, 2013.

65. Li H, Meng F, Ma J, Yu Y, Hua X, Qin J and Li Y: Insulin receptor substrate-1 and Golgi phosphoprotein 3 are downstream targets of miR-126 in esophageal squamous cell carcinoma. Oncol Rep 32: 1225-1233, 2014.

66. Meyer K, Albaugh B, Schoenike B and Roopra A: Type 1 insulin-like growth factor receptor/insulin receptor substrate 1 signaling confers pathogenic activity on breast tumor cells lacking REST. Mol Cell Biol 35: 2991-3004, 2015.

This work is licensed under a Creative Commons Attribution-NonCommercial-NoDerivatives 4.0 International (CC BY-NC-ND 4.0) License. 